\title{
Implementación de los efectos atmosféricos y de multipath en el desarrollo de un simulador de datos GNSS
}

\author{
Antonio M. Herrera Olmo, M. Clara de LACy PÉrez DE los Cobos \\ Dpto. Ingeniería Cartográfica, Geodésica y Fotogrametría, Universidad de Jaén \\ aherreraolmo@gmail.com
}

Recibido: 20/05/2014

Aceptado: 6/10/2014

\begin{abstract}
Resumen
La modernización del sistema GPS y la puesta en funcionamiento del sistema Galileo junto con otras constelaciones, mejorará las capacidades de posicionamiento de precisión. El objetivo de este trabajo es obtener un simulador de datos GNSS cercanos a los que se tendrán en el futuro y que sirva mientras tanto para poder probar y actualizar los algoritmos que se están desarrollando. Para la obtención de este objetivo, es necesario un estudio íntegro de cada uno de los términos que aparecen en la ecuación de observación GNSS y a partir de ahí emular cada uno de ellos. Aquí se presenta la primera parte del simulador, que emula los efectos ionosférico, troposférico y de multipath. Para ello se dedica una sección a cada uno de estos efectos resumiendo lo que es, como puede ser modelado y el método elegido para su simulación y posterior implementación en un script de MATLAB.
\end{abstract}

Palabras clave: Simulador GNSS, Efecto Troposférico, Efecto Ionosférico, Multipath, Matlab.

\section{Implementation of the atmospheric effects and multipath in the development of a GNSS data simulator}

\begin{abstract}
The modernization of GPS and the launch of the Galileo system along with other constellations, will improve the positioning precision. The aim of this work is to obtain a GNSS simulator data that to test and update the multifrequency algorithms that are being developed nowadays in different research centres. To obtain this objective, it is necessary to study each of the terms included in the GNSS observation equation. The first part of the simulator consists of emulating the ionospheric, tropospheric effect and multipath. This paper is devoted to each of these effects summarizing what it is, such as modeling and the method chosen for its simulation and its subsequent implementation in a MATLAB script. The final simulator will include the other terms in the equation of observation such as satellite orbits, atomic clocks and SBAS systems
\end{abstract}

Keywords: GNSS Simulator, Tropospheric Effect, Ionospheric Effect, Multipath, MATLAB.

Sumario: Introducción. 1. Ecuación de observación. 2. Efecto Ionosférico. 3. Efecto Troposférico. 4. Multipath. 5. Implementación del simulador. 6. Conclusiones y trabajos futuros. Agradecimientos. Referencias Bibliográficas.

\section{Referencia normalizada}

Herrera Olmo, A., de Lacy Pérez de los Cobos, M.C. (2014). Implementación de los efectos atmosféricos y de multipath en el desarrollo de un simulador de datos GNSS. Física de la Tierra, Vol. 26, 135-161. 


\section{Introducción}

Actualmente el sistema Galileo tiene 4 satélites en funcionamiento y se prevé totalmente operacional a partir del año 2018, mientras que el sistema GPS triple frecuencia, precursor del sistema GPS modernizado, lo estará a partir del 2019 y el sistema GPS III se espera que esté operativo en 2023 (Hofmann-Wellenhof et al. 2008). En total se dispondrá de una doble constelación formada por un total de 51 satélites multifrecuencia (27 Galileo + 24 GPS). De todas las frecuencias empleadas, cada sistema dedicará tres de ellas a proporcionar servicios de acceso libre a todos los usuarios. La presencia de nuevas frecuencias, así como, la existencia de una doble constelación de satélites contribuirá a aumentar considerablemente la redundancia de observaciones. Además, disponer de dos sistemas de navegación mejorará la cantidad y la geometría los de satélites visibles y las observaciones triple frecuencia darán lugar a un mayor número de combinaciones lineales, que deberían reducir los efectos atmosféricos y optimizar los métodos de resolución de ambigüedades y detección y corrección de saltos de ciclo (Lacy et al. 2008).

Hasta que llegue el momento del futuro escenario GNSS muchos centros de investigación están tratando de generalizar los actuales algoritmos GPS para adaptarlos al nuevo escenario. Así pues, se puede decir que se han desarrollado e implementado algoritmos multifrecuencia para detección y corrección de saltos de ciclo: Zhen et al. (2008), Dai et al. (2009), Banville and Langley (2010), Liu (2011) y Lacy et al. (2012); para la resolución de ambiguiedades: Teunissen and Odijk (2003), Ji et al. (2007), Feng (2008), Cocard et al. (2008), Feng and Rizos (2009) y Li et al. (2010); para el uso conjunto de constelaciones, para el posicionamiento y la navegación, o para el modelado del efecto ionosférico a partir de distintas combinaciones lineales de observaciones: Moreno et al. (2011) y Odijk (2003). Sin embargo la falta de datos o la presencia de simuladores "optimistas" dificultan el análisis de los resultados que se puedan obtener con estos algoritmos. Los simuladores existentes en el mercado, son en realidad emuladores de frecuencia de elevado coste, por ejemplo Spirent GSS8000 o generadores de datos GNSS muy lejanos de los que se esperan obtener en el futuro.

En este trabajo se presenta la primera parte de un simulador de datos GNSS. En la sección 1 se describe la ecuación de observación, en las secciones 2 y 3 se describen los efectos atmosféricos que afectan a la señal GNSS: efecto ionosférico y efecto troposférico, respectivamente. En la sección 4 se describe el multipath o efecto multicamino, y para terminar en la sección 5 se describe el funcionamiento del simulador de datos GNSS. Finalmente, en la sección 6 se presentan las conclusiones y los futuros trabajos. 


\section{Ecuación de observación}

Para obtener un simulador realista es necesario el estudio íntegro de cada uno de los términos que aparecen en la ecuación de observación GNSS y a partir de ahí emular cada uno de ellos. El modelo completo de la ecuación de observación GPS entre un receptor y un satélite viene dado por (Sansò 2010):

$$
\begin{gathered}
P_{i}=\rho+k_{1 i} J_{1}+\delta l+T+\sigma_{R}-\sigma^{S}+B_{i}^{S}+B_{R i}+\underline{e} \cdot\left(\underline{a}^{S}-\underline{a}_{R}\right)+M^{S} \\
-M_{R i}+v_{P i} \\
\begin{aligned}
L_{i}=\rho-k_{1 i} J_{1} & +\delta l+T+\sigma_{R}-\sigma^{S}+b_{i}^{S}+b_{R i}+\underline{e} \cdot\left(\underline{a}^{S}-\underline{a}_{R}\right)+L_{0 i} \\
& +N_{i} \Lambda_{i}+m^{S}-m_{R i}+v_{L i}
\end{aligned}
\end{gathered}
$$

donde:

$P_{i}$ es la observación de pseudodistancia o código en la frecuencia $f_{i}$ con $i=1,2,3$.

$L_{i}$ corresponde a la observación de fase expresada en unidades de distancia en la frecuencia $f_{i}$ con $i=1,2,3$.

$\rho$ representa la distancia geométrica entre receptor y satélite.

$\sigma^{S}$ y $\sigma_{R}$ son los términos asociados a los efectos del offset del oscilador del satélite y receptor respectivamente.

$T$ representa el retardo troposférico.

$J_{1}$ es el retardo de grupo ionosférico en la frecuencia $f_{l}$.

$k_{1 i}=\left(f_{1} / f_{i}\right)^{2}$, con $i=1,2,3$.

$\delta l$ representa la corrección por la curvatura sufrida por la señal al atravesar la atmósfera.

$B_{R i}, B_{i}^{S}, b_{R i}$ y $b_{i}^{S}$ corresponden a los retrasos electrónicos de código y fase, respectivamente, introducidos por receptor y satélite en la frecuencia $f_{i}$.

$\underline{a}^{S}$ y $\underline{a}_{R}$ son las excentricidades de centro de fase de satélite y receptor, respectivamente.

$\underline{e}$ es el vector unitario en la dirección receptor-satélite.

$L_{0 i}$ es el valor de fase inicial multiplicado por la correspondiente longitud de onda $\Lambda_{i}$.

$N_{i}$ es la ambigüedad de fase inicial (por definición un número entero de ciclos).

$M^{S}$ y $M_{R i}$ corresponden al efecto de multipath de código o pseudodistancia de satélite y receptor.

$m^{S}$ y $m_{R i}$ representan el efecto de multipath de fase de satélite y receptor respectivamente.

$v_{P i}$ y $v_{L i}$ son los errores aleatorios de las observaciones de código y fase respectivamente. 
Entrando ahora un poco en detalle en los términos anteriores, se puede decir que el efecto ionosférico puede ser modelado para cada rayo receptor-satélite con un error residuo de decenas de centímetros; el efecto troposférico se puede corregir también con un modelo con un error de pocos centímetros. $\sigma^{S}, b_{i}^{S}, B_{i}^{S}$ pueden conocerse a través de las efemérides y de los valores de DCB (Differential Code Bias) estimados por centros internacionales de investigación, como por ejemplo, Center for Orbit Determination en Europa (CODE) (Schaer y Steigenberger 2006); de forma análoga ocurre con $\sigma_{R}$ y $B_{R i}$ si el receptor en cuestión es una estación del IGS. En cualquier otro caso $\sigma_{R}$ y $B_{R i}$ se pueden escribir en un único término que denotaremos simplemente con $\sigma_{R}$ y que es una incógnita para cada época. La misma operación se puede aplicar $\sigma_{R}$ y $b_{R i}$ es decir a los sesgos electrónicos de fase. De proceder así los errores de offset del oscilador del receptor que aparecen en las ecuaciones de observación de código y fase no estarían alineados. Este problema se supera introduciendo el llamado valor inicial de la fase, $L_{0 i}$ que alinea los errores del oscilador del receptor en las ecuaciones de código y fase. Los valores de $\underline{a}^{S}$ y $\underline{a}_{R}$ correspondientes a los offsets y variaciones del centro de fase de las antenas pueden calcularse a partir de los ficheros oficiales proporcionados por el IGS (Internacional GNSS Service). Además, es importante añadir que los errores aleatorios de código y fase son del orden de decenas de centímetros en el primer caso y de un par de milímetros en el segundo. Los términos principales que aparecen en (1.1) tendrán que estar presentes en la observación generada por nuestro simulador. En este trabajo, sólo trataremos la parte correspondiente a la ionosfera, troposfera y al multipath, dejando para otro trabajo posterior la parte de las órbitas de los satélites, de los osciladores y el resto de los efectos.

\section{Efecto Ionosférico}

La ionosfera es un medio dispersivo, esto es la velocidad de propagación es función de la frecuencia de la onda, que está localizada en la región de la atmósfera comprendida entre $70 \mathrm{Km}$ y $1000 \mathrm{Km}$ sobre la superficie terrestre. Dentro de esta región, los rayos ultravioletas del sol ionizan una porción de las moléculas de gas y liberan electrones. Estos electrones libres influyen en la propagación de ondas electromagnéticas, incluidas las señales de los sistemas de posicionamiento satelital. De forma que la velocidad de fase excede a la velocidad de grupo, siendo el retardo de la velocidad de grupo igual al avance de la portadora de fase con respecto a la propagación en el vacío. En el caso de GPS, esto se traduce en que la señal de información (código PRN y datos de navegación) se retrasa, y la portadora de fase experimenta un avance, un fenómeno llamado divergencia ionosférica. Es decir, las pseudodistancias de las medidas de código son demasiado largas y las medidas de pseudodistancias de la portadora de fase son demasiado cortas comparadas con la distancia geométrica entre receptor y satélite en cada época considerada. Además, la 
magnitud del error en las medidas de pseudocódigo y el error en la medida de la portadora de fase (ambas en metros) son iguales, sólo su signo es diferente (Hofmann-Wellenhof et al. 1993):

$$
J_{1}=\mp \frac{40.3}{f_{i}^{2}} T E C
$$

siendo $f_{i}^{2}$ la frecuencia de la señal, con $i=1,2,3$ y TEC es el contenido total de electrones a lo largo de la columna de sección $1 \mathrm{~m}^{2}$ entre satélite y receptor. El valor de la variable TEC se expresa en TECU (TEC Units), siendo 1 TECU $=10^{16}$ electrones por $\mathrm{m}^{2}$. Usualmente, se modela el contenido total de electrones vertical (vTEC). Si se introduce vTEC en (2.1) sólo sería aplicable a satélites que se encuentren en el cenit. Por ello, para llevarlo a la dirección satélite-receptor correspondiente a cada caso, es necesario tener en cuenta el ángulo cenital del satélite que denotamos como $z$ :

$$
J_{1}=\frac{1}{\cos z} \frac{40.3}{f_{i}^{2}} v T E C
$$

se puede decir que la influencia de la ionosfera para la pseudodistancia de código es $+J_{l}$ y para la fase $-J_{l}$.

Para el cálculo de la refracción ionosférica se utilizan diversos modelos, entre los que destacan: el modelo de Klobuchar que utiliza los coeficientes ionosféricos enviados dentro del mensaje de navegación y reduce la influencia de la refracción ionosférica en al menos un 50\% (ARINC Engineering Services 2006), y el modelo de NeQuick que es el método adecuado para el modelado del TEC en las observaciones Galileo según la ITU-R (Unión Internacional de Telecomunicación, sector de Radiocomunicación). NeQuick es un modelo ionosférico de concentración de electrones capaz de dar la distribución de la densidad de electrones en la parte inferior y superior de la ionosfera. Los parámetros de entrada del modelo son posición, tiempo, y flujo solar; la salida es la concentración de electrones para un lugar y un tiempo dado. Para profundizar más en los modelos anteriores, se puede consultar Hofmann-Wellenhof et al. (2008).

Por otro lado, también existe la posibilidad de eliminar la influencia de la refracción ionosférica mediante el uso de combinaciones lineales de las observaciones, siendo la más conocida la combinación "iono-free".

Por último, hay que comentar la existencia de los modelos globales como los que vienen en formato IONEX (the IONosphere map EXchange format). Estos archivos contienen un mapa de valores TEC en función de la latitud, la longitud y el 
tiempo universal en formato IONEX. Dicho formato fue desarrollado por el Instituto Astronómico de la Universidad de Berna (Suiza) (Schaer et al. 1998). A partir de los datos de un fichero IONEX se puede calcular la refracción ionosférica mediante estos mapas de TEC:

- Tomar simplemente el valor de TEC más cercano.

- Interpolar linealmente entre dos valores de TEC consecutivos.

- Interpolar linealmente entre dos mapas de TEC consecutivos rotados.

- Algoritmo de interpolación bilineal.

Este último método de interpolación bilineal es el que se ha utilizado en nuestro simulador para reproducir el retardo ionosférico. La función $\frac{1}{\cos z}$ será la que se utilice para proyectar el efecto ionosférico en la dirección receptor-satélite.

\section{Efecto Troposférico}

La troposfera se encuentra en la parte baja de la atmósfera y es un medio no dispersivo para frecuencias de hasta $15 \mathrm{GHz}$. Este retraso es una función del índice de refracción de la troposfera, que depende de la temperatura local, la presión y la humedad relativa. La distancia equivalente que produce este retardo, puede variar desde los $2.4 \mathrm{~m}$ para un satélite que se encuentre en el cenit y un usuario a nivel del mar, hasta los $25 \mathrm{~m}$ para un satélite con un ángulo de elevación de aproximadamente $5^{\circ}$ (Hofmann- Wellenhof et al. 2008). La desventaja es que no se puede eliminar la refracción troposférica mediante combinaciones lineales de observaciones con distintas frecuencias.

El retardo troposférico se puede dividir en dos componentes, una seca y otra húmeda, el $90 \%$ de la refracción troposférica proviene de la componente seca, y el $10 \%$ restante lo aporta la componente húmeda.

Existen distintos modelos para calcular el efecto troposférico. El modelo de Hopfield (1969) utiliza datos reales que cubren toda la superficie terrestre, y dispone de una representación empírica tanto para la componente seca como para la componente húmeda. El modelo de Saastamoinen (1973) calcula el efecto troposférico a partir de las leyes de los gases. Es importante resaltar que los modelos de Hopfield y Saastamoinen cambian los valores de troposfera cuando cambian las condiciones meteorológicas ( $p, T$ y $e$, presión, temperatura y vapor de agua). Cuando en el lugar de observación se toman datos meteorológicos los valores de la troposfera cambian a lo largo del día. La presión del vapor de agua, $e$, es difícil de medir por lo que normalmente no se toman datos, si no que se propagan los valores correspondientes al nivel del mar al lugar de observación en función de la altura de la estación.

Los modelos anteriores dan un único valor de troposfera a lo largo del día y a lo largo del año, que cambia únicamente en función de la elevación del satélite. Para 
solucionar esta deficiencia se introduce el modelo global de presión y temperatura. El modelo empírico GPT (Global Pressure and Temperature) (Boehm et al., 2007), que se basa en armónicos esféricos de hasta grado y orden nueve, proporciona la presión y la temperatura para cualquier lugar en la superficie terrestre. Los parámetros de entrada del modelo GPT son: las coordenadas del usuario y el día del año, por tanto, también permite al modelo variaciones anuales de los parámetros.

La determinación del modelo empírico GPT se basa en 3 años de datos meteorológicos. Se utiliza una malla global de $15^{\circ} \times 15^{\circ}$ de valores medios mensuales, de presión y temperatura, proporcionada por ECMWF (European Centre for MediumRange Weather Forecast, Centro Europeo de Predicción Meteorológica a Medio Plazo). Entonces, por cada punto de la malla hay 36 valores medios mensuales (uno por cada mes de los tres años) de presión y temperatura al nivel medio de mar (MSL, Mean Sea Level). Para estas dos series, los valores medios, $a_{0}$, y las amplitudes anuales, A, se estiman con el desfase fijo del 28 de enero (Niell 1996), donde doy es el día del año:

$$
a=a_{0}+A \cdot \cos \left(\frac{d o y-28}{365.25} 2 \pi\right)
$$

Los residuos para este modelo son mayores de $20 \mathrm{hPa}$ para la presión y $10^{\circ} \mathrm{C}$ para la temperatura en altas latitudes; los residuos son significativamente menores en latitudes más cercanas al ecuador, consistente con la variabilidad meteorológica. En el siguiente paso, cada una de la cuatro mallas (valores medios al MSL y amplitudes anuales de presión y temperatura) se desarrolla en armónicos esféricos hasta grado y orden nueve, obteniéndose la malla de valores medios, $\mathrm{a}_{0}$.

$$
a_{0}=\sum_{n=0}^{9} \sum_{m=0}^{n} P_{n m}(\sin \varphi) \cdot\left[A_{n m} \cos (m \lambda)+B_{n m} \sin (m \lambda)\right]
$$

donde los $P_{n m}$ son los polinomios de Legendre (Heiskanen y Moritz 1967), $\varphi$ у $\lambda$ son latitud y longitud, y $A_{n m}$ y $B_{n m}$ son los coeficientes para grado $n$ y orden $m$ que se determinan con ajuste de mínimos cuadrados. GPT utiliza (3.2) para obtener el valor medio, $a_{0}$, y una ecuación similar para la amplitud, $A$. Estos valores se introducen en (3.1) junto con el doy para obtener la presión o la temperatura al MSL. Los valores constantes de referencia de presión y temperatura (medias anuales) se pueden derivar de la ecuación (3.1) si $(28+365.25 / 4)$ se utiliza como doy. Una vez calculados los valores de presión y temperatura al MSL, se introducen en las siguientes expresiones junto con la altura ortométrica, 


$$
\begin{gathered}
p=p_{R}\left[1-0.0000226\left(h-h_{0}\right)\right]^{5.225} \\
\frac{d T}{d h}=-0.0065^{\circ} \mathrm{C} / \mathrm{m}
\end{gathered}
$$

para obtener la presión y la temperatura en cualquier lugar, donde $h$ es la altura sobre la superficie de la Tierra, y $p_{r}$ es la presión existente al nivel medio del mar $h_{0}$. GPT permite también el uso de la altura elipsoidal como entrada, ya que no siempre se dispone de la altura ortométrica del punto de observación. Para realizar la trasformación de altura elipsoidal en ortométrica se debe utilizar el modelo de geoide que mejor se ajuste a la zona del usuario.

Por último, comentar las funciones de mapeado de la troposfera, que se utilizan en el análisis de observaciones GPS para proyectar, a priori, los retardos producidos por el ángulo de elevación entre el receptor y el satélite, en las componentes hidrostática y húmeda. Esta función, al igual que GPT, se basa en datos del modelo numérico del ECMWF. Los coeficientes de GMF (Global Mapping Function) se obtienen de un desarrollo de los parámetros de la Vienna Mapping Function (VMF1) (Boehm 2006) en armónicos esféricos en una red global. El retardo en la dirección de observación está relacionado con el ángulo cenital que existe entre receptor y satélite, mediante una función de mapeado. Esta función modela el retardo, con suficiente precisión para elevaciones de hasta $3^{\circ}$, con una fracción continua de tres términos en seno de $E$ (Niell 1996):

$$
m f(E)=\frac{1+\frac{a}{1+\frac{b}{1+c}}}{\sin (E)+\frac{a}{\sin (E)+\frac{b}{\sin (E)+c}}}
$$

donde $E$ es la elevación del satélite, y los parámetros $a, b$ y $c$ son diferentes para la componente hidrostática y húmeda de la atmósfera. Para determinar estos coeficientes se utiliza, como en la sección anterior, una malla de $15^{\circ} \times 15^{\circ}$ de valores medios mensuales, de presión, temperatura y humedad, proporcionada por ECMWF. Los coeficientes $a_{h}$ (componente hidrostática) y $a_{w}$ (componente húmeda) se determinaron con datos del período comprendido entre septiembre de 1999 y agosto de 2002 aplicando la misma estrategia que utiliza VMF1. Tomando las ecuaciones empíricas para $b$ y $c$ (de VMF1) los parámetros $a$ se obtienen con un simple trazado de rayos con un ángulo de elevación inicial de $3.3^{\circ}$. 


\section{Multipath}

El efecto queda bien descrito por su nombre: la señal emitida por el satélite llega al receptor por más de un camino. El multipath se produce principalmente por superficies reflectantes cerca del receptor. En la figura 1, se puede observar como la señal enviada por el satélite llega al receptor por tres caminos diferentes, uno directo y dos indirectos. Debido a esto, las señales recibidas tienen un cierto desfase, que es proporcional a la longitud de los caminos recorridos. No existe un modelo general del efecto multipath porque depende de la situación geométrica de cada caso en particular. Sin embargo, la influencia del multipath se puede estimar utilizando una combinación de medidas de código y fase para las frecuencias $f_{1}$ y $f_{2}$. El principio se basa en el hecho de que, tanto la troposfera como los errores producidos por el reloj influyen en la misma medida en el código y la fase. Pero esto no ocurre con la refracción ionosférica y el multipath, ya que estos dependen de la frecuencia. Aplicando la combinación iono-free para el código y la fase, y construyendo las diferencias, todos los efectos mencionados excepto el multipath se cancelan (HofmannWellenhof et al. 2008).

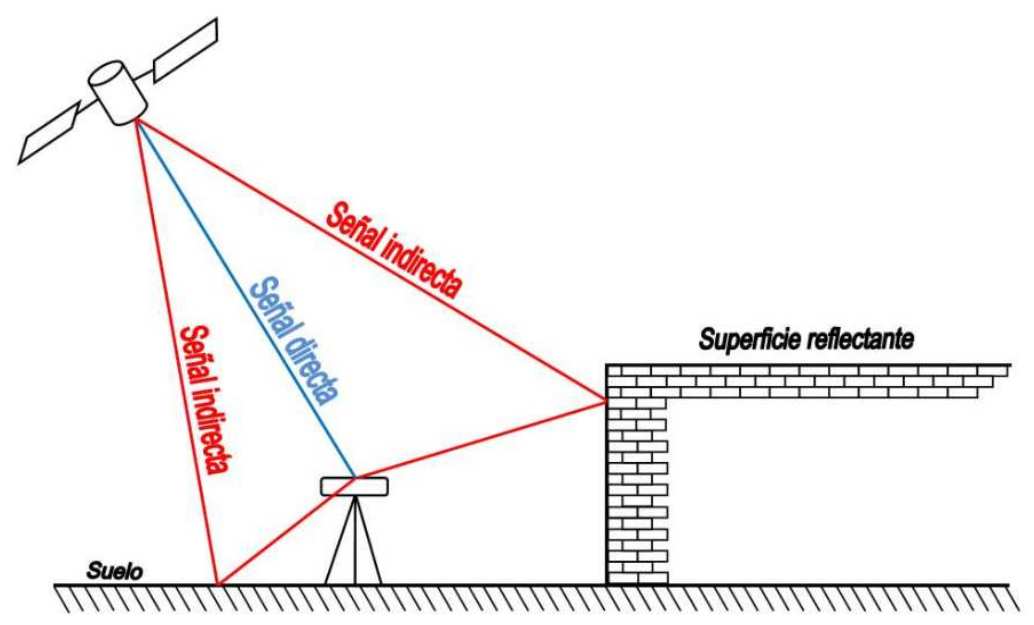

Fig. 1. Efecto Multipath.

En términos geométricos, es evidente que las señales recibidas de satélites con baja elevación son más susceptibles de generar multipath que las recibidas de satélites con alta elevación. Además, el multipath afecta más a las medidas de código que a las de fase. Comparando época a época, el multipath puede afectar las pseudodistancias calculadas mediante el código en 10-20 m (Wells et al. 1987). Bajo ciertas condiciones extremas, el error provocado por el multipath puede llegar 
a valores de unos $100 \mathrm{~m}$ en entornos urbanos (Nee 1992), e incluso puede provocar la pérdida de señal.

El efecto multipath sobre la portadora de fase en posicionamiento relativo para líneas de base cortas, generalmente, no debe ser mayor a $1 \mathrm{~cm}$ (con buena geometría de los satélites y un período de observación razonablemente largo). Cuando se realizan medidas en estático, con intervalos de observación largos, los períodos intermitentes de multipath no son un problema. Esto puede ocurrir, por ejemplo, si la antena del receptor está situada cerca de una autopista y hay tráfico de vehículos grandes, tales como camiones metálicos. Para el caso de medidas estáticas rápidas (es decir, con períodos de observación cortos) si supone un problema, y es aconsejable alargar el tiempo de observación, cuando pueda hacerse.

El efecto multipath, típicamente, tiene características senoidales. El tamaño del error depende de cuatro factores principalmente: superficies reflectantes en el entorno, geometría satélite-antena, el tipo de antena, y el tipo de receptor. Las superficies reflectantes producen un efecto multipath de gran amplitud, los objetos cercanos producen multipath de período largo y los más alejados provocan errores con longitudes de onda cortas. El ángulo de elevación del satélite es un factor geométrico clave: las oscilaciones producidas por el efecto multipath tiene períodos más cortos para bajas elevaciones del satélite que para altas elevaciones.

Existen numerosos estudios del efecto multipath llevados a cabo por diversos autores, por ejemplo, Larson et al. (2007) dividen la periodicidad del efecto multipath en tres grupos, según el estudio realizado en la red SCIGN (Southern California Integrated GPS Network): período muy corto (entre 25 y 50 segundos), período corto (entre 30 y 100 segundos) y período largo (entre 300 y 3000 segundos). Por otro lado, Ogaja y Satirapod (2007) hacen únicamente dos grupos: período corto (entre 10 y 50 segundos) y período largo (mayor de 50 segundos). Ambos autores coinciden que el efecto multipath con período de 20 segundos $(0.05 \mathrm{~Hz})$ es el más interesante, ya que tiene un período cercano a las ondas sísmicas de superficie. Por lo tanto, es necesario eliminar este tipo de multipath para no ocasionar errores en los estudios sísmicos.

Para la detección de este efecto multipath de período corto hay que analizar series de datos muestreadas a un segundo. Almacenar datos a un segundo supone un gran volumen de información, pero el precio de las unidades de almacenamiento cada vez es más bajo, por esta razón, el número de estaciones permanentes GPS que operan a $1 \mathrm{~Hz}$ cada vez es mayor, permitiendo así el estudio del efecto multipath.

Otra característica bien conocida por los usuarios de GPS es que la constelación se repite: los mismos satélites aparecen en el mismo lugar en el cielo con un período de tiempo ligeramente menor a un día. Existe una regla práctica que aproxima este valor a 4 minutos ( 240 segundos). Una regla más exacta utiliza el día sidéreo (235.9 segundos menor que un día solar). En este día sidereo, un satélite completaría exactamente dos órbitas y la Tierra una revolución, volviendo todo a la misma geometría. En un estudio realizado por Agnew y Larson (2006) se muestra que el 
valor del período de tiempo ligeramente menor a un día es distinto para cada satélite, y concluyen que la mejor forma de corregir el multipath es procesando los datos de cada satélite por separado, en vez de trabajar con series de datos de posiciones. Otro estudio realizado también por Larson et al. (2007) utiliza dos métodos para determinar el período de tiempo ligeramente menor a un día óptimo de desplazamiento en las series temporales: utilizando la correlación cruzada o minimizando la diferencia en error cuadrático medio para un rango de desplazamientos. Esta repetición de la constelación GPS se puede explotar para detectar el multipath. En el siguiente apartado se explica cómo aprovechar esta característica.

En nuestro modelo los residuos representan la suma del error debido al multipath y el causado por la electrónica del receptor. El análisis de los residuos nos puede dar información tanto de las características de multipath, como de las propiedades estocásticas de ruido del receptor. Para estimar el ruido del receptor es necesario eliminar la componente de multipath. Esto es posible ya que el multipath es un efecto sistemático, y además está relacionado con el lugar y la configuración de satélites para cada época de observación. Como ya se comentó anteriormente, la configuración de satélites se repite cada día con un adelanto de unos cuatro minutos, por tanto es posible eliminar los efectos del multipath restando los residuos de dos días consecutivos, cuando la configuración de satélites es la misma (Baiocchi et al. 2007):

$$
\begin{gathered}
v_{1}=M P+v_{1} \\
v_{2}=M P+v_{2} \\
v_{2}-v_{1}=M P+v_{2}-M P-v_{1}=v_{2}-v_{1}=\Delta v
\end{gathered}
$$

donde $v_{i}$, con $i=1 ; 2$ son los residuos de dos días consecutivos, $M P$ es el efecto multipath y $v_{i}$, con $i=1 ; 2$ son los errores del ruido del receptor en dos días consecutivos.

Si se suman los residuos, de dos días consecutivos con la misma configuración de satélites, el efecto multipath se duplica y es más sencillo de detectar, ya que:

$$
v_{2}+v_{1}=M P+v_{2}+M P+v_{1}=2 M P+v_{2}+v_{1}
$$

Esta estrategia se va a utilizar para obtener los patrones de multipath que se van a implementar en el simulador.

\subsection{Técnicas de análisis espectral para la detección del multipath}

Existen varias técnicas para el análisis espectral, aquí se van a describir las más interesantes para la detección del multipath. Si el lector está interesado en profundi- 
zar en estas y otras técnicas, puede consultar Proakis y Manolakis (2007) y Oppenheim et al. (1999).

\subsubsection{Espectrograma (STFT)}

En la práctica, las propiedades de la señal, amplitud frecuencia y fases, cambian con el tiempo. Una Transformada Discreta de Fourier (DFT) no es suficiente para representar este tipo de señales, porque se pierde información en el tiempo. La Short-Time Fourier Transform (STFT) soluciona este problema de pérdida de información tomando ventanas de tiempo de la señal de estudio. Entonces se ralizan transformadas de Fourier de cada ventana manteniendo así la información temporal.

La STFT de una señal $x[n]$ está definida (Oppenheim et al. 1999):

$$
X[n, \lambda)=\sum_{m=-\infty}^{\infty} x[n+m] w[m] e^{-j \lambda m}
$$

donde $w[m]$ es la secuencia de una ventana. En esta representación de Fourier dependiente del tiempo, la secuencia unidimensional $x[n]$, se convierte en una bidimensional, la variable de tiempo $n$, que es discreta, y la frecuencia variable $\lambda$, que es continua (en la ecuación se utiliza corchete y paréntesis para indicar esta característica). Nótese que la STFT es periódica en $\lambda$ con período $2 \pi$.

La ecuación (4.3) se puede interpretar como la transformada de Fourier de una señal desplazada $x[n+m]$ vista a través de la ventana $w[m]$.

Siendo $X[n, \lambda)$ la transformada discreta de Fourier de $x[n+m] w[m]$, la STFT es invertible si la ventana utilizada tiene al menos una muestra distinta de cero. Utilizando la ecuación de síntesis de la transformada de Fourier se tiene:

$$
x[n+m] w[m]=\frac{1}{2 \pi} \int_{0}^{2 \pi} X[n, \lambda) e^{j \lambda m} d \lambda, \quad-\infty<m<\infty
$$

de donde

$$
x[n]=\frac{1}{2 \pi w[0]} \int_{0}^{2 \pi} X[n, \lambda) d \lambda, \quad \text { si } \quad w[0] \neq 0
$$




\subsubsection{Análisis espectral usando la estimación de la secuencia de autocorrelación}

Este enfoque se basa en que la densidad espectral de potencia es la transformada de Fourier de la función de autocorrelación. Por tanto, primero realiza una estimación de la función de autocorrelación de la secuencia para después aplicar la transformada de Fourier a esta estimación (Oppenheim et al. 1999).

Se toman un número finito de valores $Q$, de la secuencia aleatoria $x[n]$ :

$$
v[n]=\left\{\begin{array}{cc}
x[n], & 0 \leq n \leq Q-1 \\
0 & \text { en otro caso }
\end{array}\right.
$$

Considerando la estimación de la secuencia de autocorrelación como:

$\hat{\phi}_{x x}[m]=\frac{1}{Q} c_{v v}[m]$

siendo $c_{v v}[-m]=c_{v v}[m]$, la correlación aperiódica de un segmento de $x[n]$ enventanado con la ventana rectangular.

$$
c_{v v}[m]=\sum_{n=0}^{Q-1} v[n] v[n+m]=\left\{\begin{array}{cl}
\sum_{n=0}^{Q-|m|-1} x[n] x[n+|m|], & |m| \leq Q-1 \\
0 & \text { en otro caso }
\end{array}\right.
$$

Ahora, se puede definir la estimación del espectro de potencia como:

$$
S(\omega)=\sum_{m=-(M-1)}^{M-1} \widehat{\phi}_{x x}[m] w_{c}[m] e^{-j \omega m}
$$

donde $w_{c}[m]$ es una ventana simétrica de longitud $(2 M-1)$ aplicada a la función estimada de autocorrelación.

\subsubsection{Análisis Wavelets}

Este análisis utiliza una serie de funciones madre, en lugar de funciones senoidales como hace la transformada de Fourier. La traducción del término wavelets al castellano es "onditas", cada familia tiene una forma de onda distinta a las demás, figura 2a). 
a)
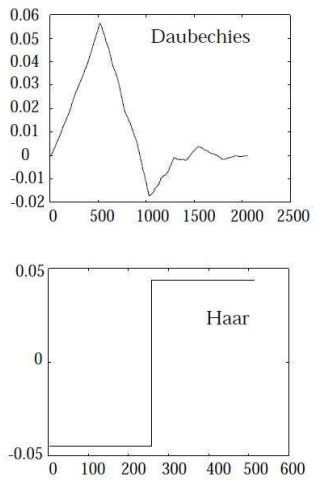

b)
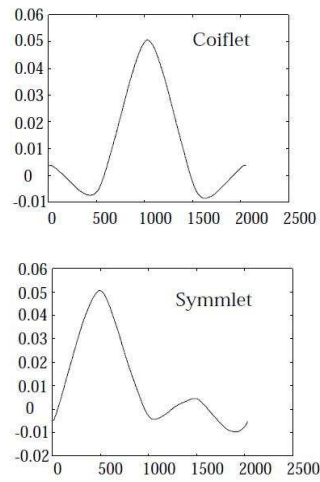

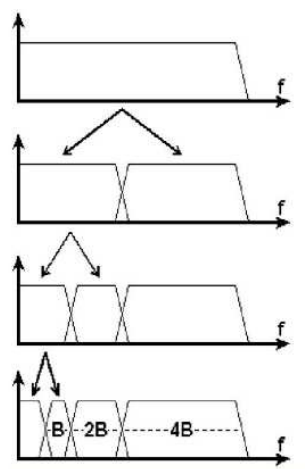

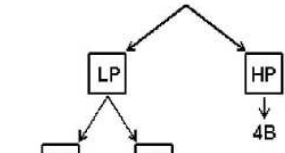

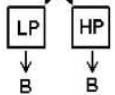

Fig.2. a) Algunas familias de wavelets (Graps 1995). b) Esquema jerárquico de wavelets.

Mediante dilataciones y translaciones de la función madre elegida $\Phi(x)$, se define una base ortogonal, la base wavelet:

$$
\Phi_{(s, l)}(x)=2^{-\frac{s}{2}} \Phi\left(2^{-s} x-l\right)
$$

las variables $s$ y $l$ son valores enteros que escalan y dilatan la función madre $\Phi$ para generar las wavelets. El índice de escala $s$ indica el ancho de la onda y el índice de localización $l$ da su posición. Nótese que las funciones madre son dilatadas por potencia de dos, y desplazadas por un valor entero (Graps 1995). Para obtener las distintas resoluciones, el análisis wavelet utiliza una ecuación de escala:

$$
W(x)=\sum_{k=-1}^{N-2}(-1)^{k} c_{k+1} \Phi(2 x+k)
$$

donde $W(x)$ es la función de escalado para la función madre, y $c_{k}$ son los coeficientes wavelets. Los coeficientes wavelets deben satisfacer el constreñimiento linear y cuadrático de la forma:

$$
\sum_{k=0}^{N-1} c_{k}=2, \quad \sum_{k=0}^{N-1} c_{k} c_{k+2 l}=2 \delta_{l, 0}
$$


donde $\delta$ es la función delta y $l$ es el índice de localización.

Una característica importante es que ofrecen la posibilidad de definir distintos coeficientes para adaptarse a un problema dado. Por ejemplo, existen familias wavelets con un buen comportamiento en representaciones polinomiales como Daubechies (Daubechies 1988).

Los coeficientes $\left\{c_{0}, \ldots, c_{n}\right\}$ pueden verse como un filtro. El filtro o los coeficientes se colocan en una matriz de transformación que se aplica a los datos. La matriz se aplica mediante un algoritmo jerárquico, también llamado algoritmo piramidal. Así, se obtienen las señales de aproximación o tendencia y detalle, figura 2 b). La señal de aproximación o tendencia contiene señales de baja frecuencia, y las de detalle tienen señales de frecuencias más altas que la de aproximación. En el siguiente apartado se presenta un análisis con datos GPS para ilustrar el funcionamiento de este método para la extracción de patrones de multipath.

\section{Implementación del simulador}

El objetivo final del simulador es generar señales GNSS realistas que puedan ser utilizadas para probar algoritmos multifrecuencia durante el período de ausencia de datos triple frecuencia. El simulador deberá por tanto emular cada uno de los términos presentes en la ecuación (1.1) y en la tercera ecuación que aparecería al considerar el sistema GPS modernizado o Galileo. En este trabajo se ha realizado la parte correspondiente a los efectos de troposfera, ionosfera y multipath. Para ello, se han realizado varios script en MATLAB. En la figura 3 se presentan las opciones del simulador relativas a este trabajo. En las subsecciones posteriores se explicará detalladamente cómo se han diseñado cada uno estos efectos.

\subsection{Simulación del efecto ionosférico}

Para la simulación del efecto ionosférico se ha optado por el uso de modelos globales de TEC en formato IONEX. La razón de no utilizar los modelos de Klobuchar o NeQuick es que el primero es el que se usa para procesar datos GPS en tiempo real y el segundo ha sido elegido como modelo oficial que será utilizado para mitigar el efecto ionosférico en los datos Galileo. Si nuestro simulador generara sus datos con estos modelos, al procesarlos después con los mismos modelos estaríamos introduciendo y eliminando exactamente los mismos valores, lo que no parece en absoluto realista. Para ello, se ha optado por generar los datos con mapas globales empíricos de TEC que luego serán procesados con alguno de los modelos mencionados anteriormente, dejando por tanto una parte residual y acercándose más a la realidad. 


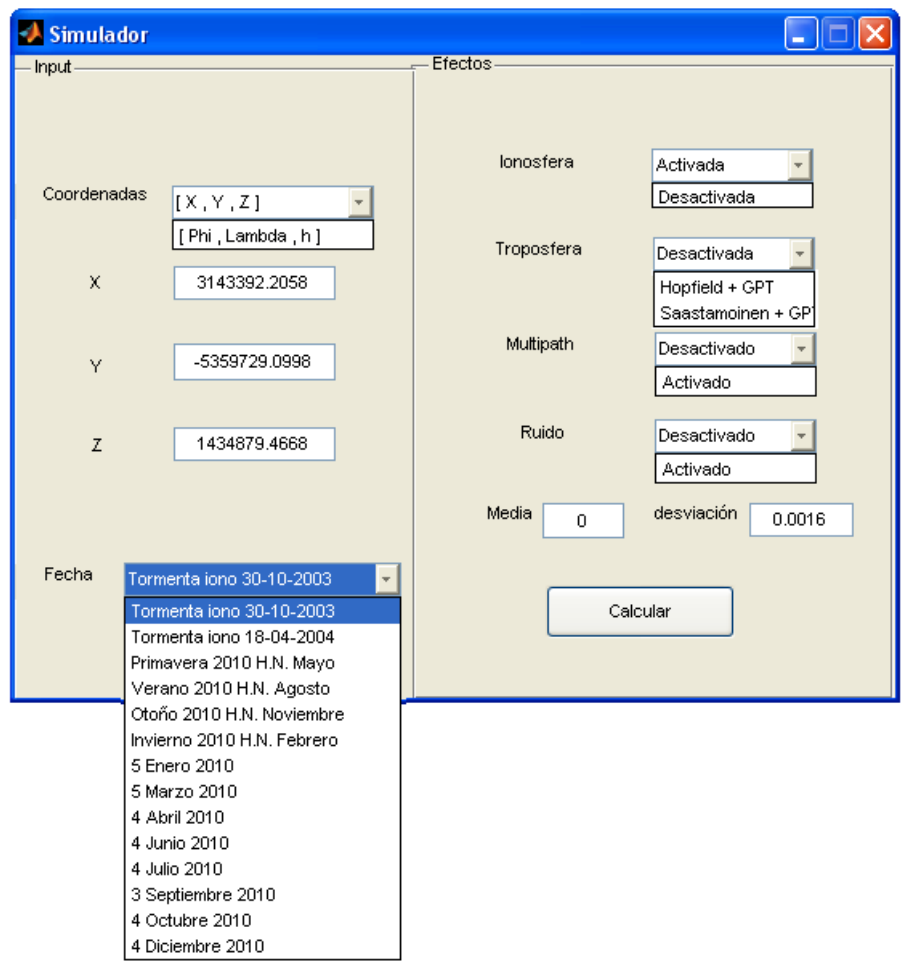

Fig. 3. Guide de MATLAB: Simulador.

Hay un archivo por cada día y cada uno de estos archivos contiene datos TEC cada dos horas para cualquier punto de la superficie terrestre. Mediante un script de MATLAB se leen los datos del fichero IONEX, y utilizando el algoritmo de interpolación bilineal comentado en la sección 2 para calcular el valor de TEC, se obtienen los valores del efecto ionosférico para unas coordenadas introducidas por el usuario. A partir de este script y teniendo en cuenta que el efecto ionosférico depende de la actividad solar y por tanto de las estaciones, se ha creado una librería con datos ionosféricos para distintas estaciones del año y para distintos meses. Además se han incluido algunos datos de tormentas ionosféricas (Moreno et al. 2011).

El usuario introduce las coordenadas del lugar de observación y la fecha correspondiente asociada a las características de ionosfera que quiere simular. A continuación se muestra un ejemplo para la estación permanente de Mali el día 10 de abril de 2010. Se ha elegido esta estación porque en ella fue detectada en el año 2003 una tormenta ionosférica y por tanto se puede simular el efecto ionosférico en condiciones normales y anormales y compararlos. Los valores obtenidos (en metros) 
corresponden con $J_{1}$ para la frecuencia L1 y con $J_{2}=k_{12} J_{1}$ para la frecuencia L2 como muestra la ecuación 1.1. La figura 4a) muestra el retardo ionosférico en condiciones medias para un satélite en el cénit. En este caso se muestran las dos frecuencias para que el lector pueda apreciar que la ionosfera se trata de un medio dispersivo, ya que no afecta igualmente a ambas frecuencias. Nótese también que el efecto ionosférico es menor durante la noche y mayor durante las horas centrales del día.

a)

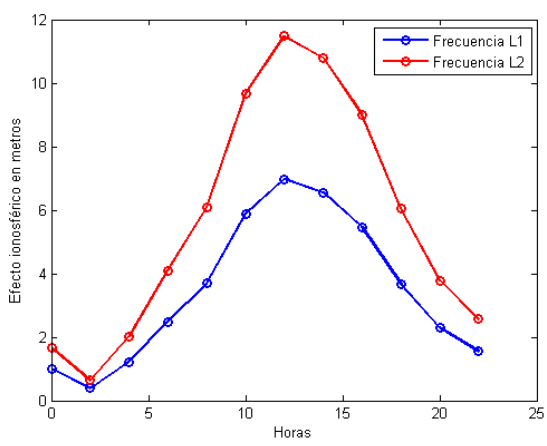

c)

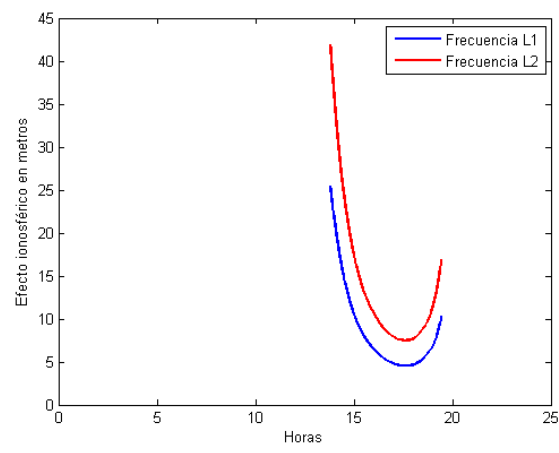

b)

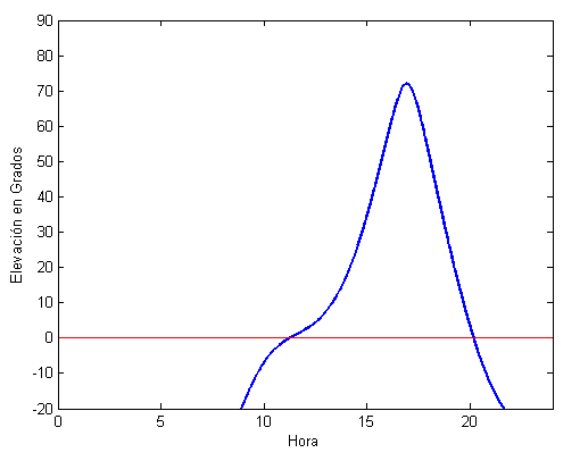

d)

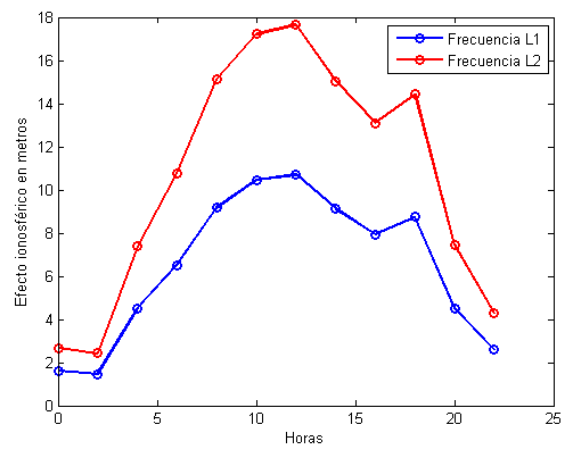

Fig. 4. a) Ejemplo de retardo ionosférico (m) en condiciones medias simulado a lo largo del día para un satélite en el cenit. b) Ejemplo de elevación del satélite $G 17\left(^{\circ}\right)$. c) Ejemplo del retardo ionosférico $(\mathrm{m})$ proyectado en la dirección satélite-receptor. d) Ejemplo del retardo ionosférico $(\mathrm{m})$ en condiciones de tormenta ionosférica simulado a lo largo del día para un satélite en el cenit.

En la figura 4b) aparecen los datos referentes a la elevación del satélite G17, estos se utilizan para obtener el retardo ionosférico real, puesto que en satélites con baja elevación la señal atraviesa una capa más espesa de ionosfera y por tanto el 
valor del efecto ionosférico es mayor. Los resultados teniendo en cuenta el valor de la elevación del satélite G17 para el cálculo del retraso ionosférico, se muestran en la figura 4c). Se puede observar que cuando el satélite está en el punto más alto el retardo es menor, unos 4 ó 5 metros, por el contrario, a baja elevación el valor del retardo es mayor, y se transforma en una distancia de 25 metros, para la frecuencia L1. Por último aparece la figura 4d), en esta simulación se han utilizado datos de la tormenta ionosférica del 30 de octubre de 2003 en la estación permanente de Mali. Se puede apreciar que la diferencia es de unos 6 metros entre el efecto ionosférico del día 10 de abril de 2010 y el 30 de octubre de 2003. Las razones pueden ser los sesgos electrónicos y las diferentes condiciones ionosféricas. Es de resaltar el pico que presenta el efecto simulado el 30 de octubre cercano a las $19 \mathrm{~h}$., correspondiente a la tormenta ionosférica detectada ese día, tal y como se explica en Bergeot et al. (2010).

\subsection{Simulación del efecto troposférico}

La troposfera se ha calculado utilizando los modelos de Hopfield y Saastamoinen expuestos en la sección 3. Ambos modelos dependen de los valores de $p, T$ y $e$, siendo presión atmosférica en milibares $(\mathrm{mb})$, temperatura en grados Kelvin $(\mathrm{K})$ y presión parcial de vapor de agua en milibares, respectivamente. Estos valores se pueden obtener mediante una estación meteorológica en el lugar de observación o se propagan los valores de $p, T$ y $e$ del nivel del mar a la altitud de la estación en cuestión, lo que proporciona un valor de efecto troposférico único durante el día y durante el año que cambia únicamente con la elevación del satélite. Para evitar esta situación poco realista, nuestro simulador propone utilizar el modelo empírico GPT (Global Pressure and Temperature) que proporciona los valores de presión atmosférica y temperatura, teniendo en cuenta variaciones estacionales. Para ello es necesario introducir las coordenadas del lugar de observación y el día del año.

Una comparación, para la estación permanente EBRE (España), con distintas opciones de modelado de la troposfera se presenta en la figura 5a). Por un lado se utiliza el modelo de Hopfield con valores $p, T$ y $e$ propagados a la altura de la estación, además se incluyen tanto el modelo de Hopfield como el de Saastamoinen, pero con los valores $p, T$ y $e$ obtenidos a partir de GPT. Para comprobar que estos datos se ajustan a la realidad se ha utilizado un fichero ZPD (Zenit Path Delay) de valores de troposfera en el cénit, estimado a partir de observaciones realizadas en la propia estación. El IGS (International GNSS Service) ofrece este tipo de ficheros para ciertas estaciones. Para tener en cuenta la elevación del satélite, se utiliza la función global de mapeado (GMF) explicada en la sección 3. Esta función proyecta los retardos producidos por el ángulo de elevación entre receptor y satélite, en las componentes hidrostática y húmeda. Para apreciar las diferencias entre los distintos modelos se ha hecho zoom en la figura $5 b$ ). Se observa claramente que introduciendo GPT en los modelos de Hopfield y Saastamoinen se obtienen resultados muy próximos a los obtenidos mediante archivos .ZPD. No se utilizan los ficheros .ZPD 
para implementar el simulador ya que sólo algunas estaciones disponen de estos datos. Es decir, este fichero .ZPD no es una malla global donde se encuentran los valores del efecto troposférico de cualquier punto de la Tierra y por tanto optamos por utilizar los modelos de Hopfield y Saastamoinen junto con los datos de GPT que se aproximan a la realidad.

a)

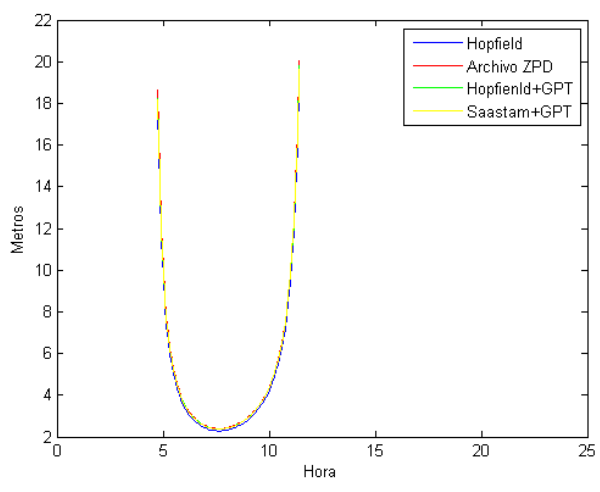

b)

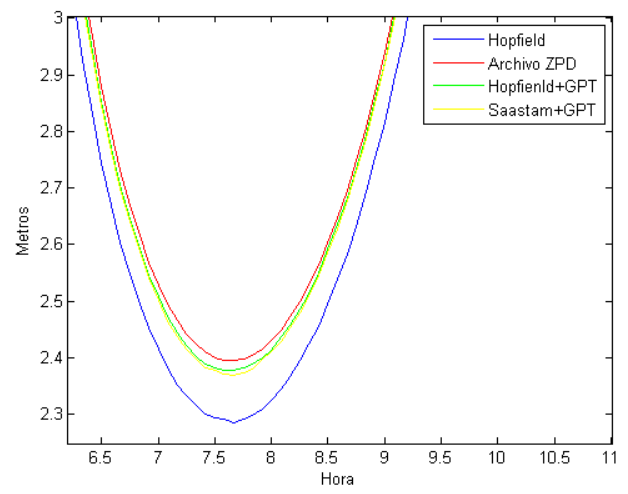

Fig. 5. a) Comparación entre las distintas opciones de modelado de la troposfera: Hopfield con condiciones meteorológicas propagadas al lugar de observación, Hopfield con GPT, Saastamoinen con GPT y archivo .ZPD. b) Zoom.

\subsection{Simulación de patrones del efecto multipath}

Esta sección se compone principalmente de dos partes: detección del efecto multipath y extracción de patrones. Antes de comenzar, decir que, para el diseño de esta parte fueron necesarios datos afectados por el efecto multipath. En un primer momento y para poder contrastar nuestro método, se solicitaron los datos de un estudio realizado en Australia (Ogaja y Satirapod 2007). Una vez verificado que se obtenían resultados coherentes con los obtenidos por estos autores se realizó un experimento $(11,12$ y 13 de junio de 2010) para obtener datos propios. Como ya es sabido, el efecto multipah depende en gran medida de la posición del receptor. Por tanto, para obtener datos con multipath se eligió un lugar con las características necesarias para recoger datos con este efecto. El lugar utilizado para la colocación de los receptores fue próximo al edificio B-5 de la Universidad de Jaén, ya que uno de sus laterales está cubierto por placas solares, cuya superficie es muy reflectante, (ver figura 6). 
a)

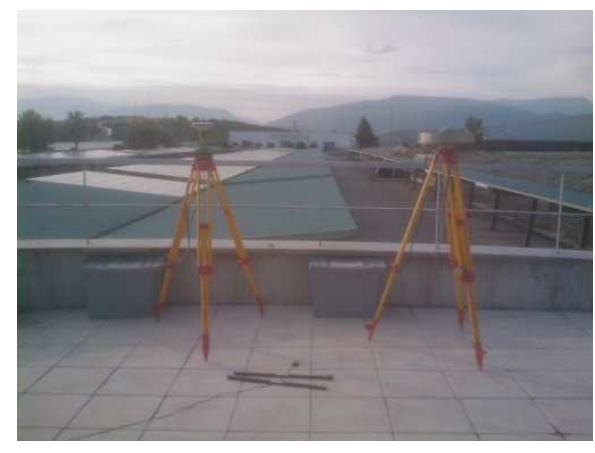

b)

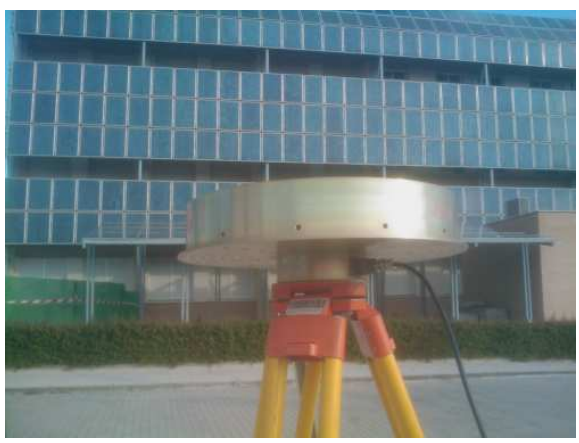

Fig. 6. a) Lugar utilizado para la recogida de datos frente al edificio B-5 de la Universidad de Jaén. b) Antena choke ring LEIAT504.

En la figura 7 se muestra el esquema del experimento realizado el 11, 12 y 13 de junio de 2010. El hecho de utilizar una antena choke ring es porque ésta mitiga el multipath y permitía comparar los resultados obtenidos con una antena LEIAX1202 que no tiene esta característica. El uso de splitter es para poder calcular las líneas de base de longitud cero y analizar sus residuos que deberían estar libres de multipath. En este trabajo sólo se presenta la parte de detección y extracción de multipath en un receptor GX1230 con antena LEIAX1202 y no se incluye la parte correspondiente al análisis de las líneas de base de longuitud cero.

Una vez obtenidos los datos fueron descargados con LEICA Geo Office para obtener los ficheros RINEX. Estos ficheros son la entrada del software en MATLAB que utiliza la primera parte del método de posicionamiento absoluto de precisión (PPP) (Moreno et al. 2013) para obtener los residuos que posteriormente son usados para el análisis de multipath. Se utiliza este método en lugar de trabajar en relativo y analizar coordenadas como hacen otros autores (por ejemplo, Larson et al. en 2007) porque trabajando con observaciones no diferenciadas es más fácil detectar el multipath. Utilizando dobles diferencias es más difícil saber a partir del análisis de los residuos que satélite es el que está afectado de multipath. Posteriormente, aprovechando el tiempo de repetición de la constelación GPS y analizando la suma y resta de residuos tal y como se explica en la sección 4, se obtienen las series temporales con las que se trabaja en la detección y extracción de patrones de multipath. En las siguientes secciones se detallan las técnicas utilizadas y los resultados obtenidos. 


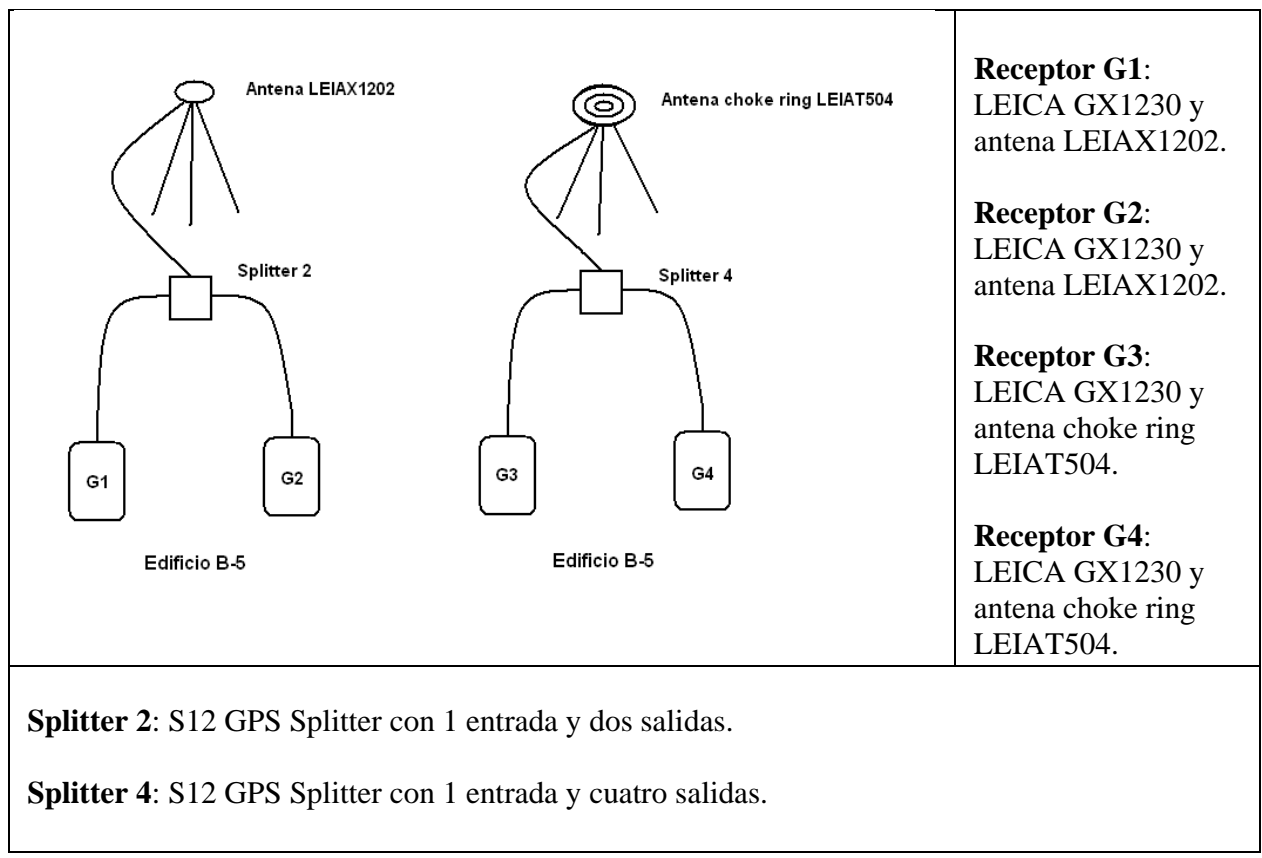

Fig. 7. Esquema del experimento realizado.

\subsubsection{Detección del efecto multipath}

Conociendo las características del multipath explicadas en la sección 4, se aplican las técnicas de análisis espectral para su detección. Ahora se describen los resultados obtenidos por el software de detección para los datos recogidos en el experimento. Primero, se muestra la elevación del satélite G09 y las series temporales de los residuos obtenidos para el código y la fase de la frecuencia L1, ver figura 8a). A continuación, se calcula la serie temporal que se utiliza en el análisis espectral como la suma de las series temporales de los residuos obtenidos durante el mismo período de observación en dos días consecutivos tal y como se ha explicado en la sección 4. Recordar que las series temporales se suman teniendo en cuenta el desfase de 4 minutos que existe entre las constelaciones de satélites en dos días consecutivos, figura $8 b)$. 
a)
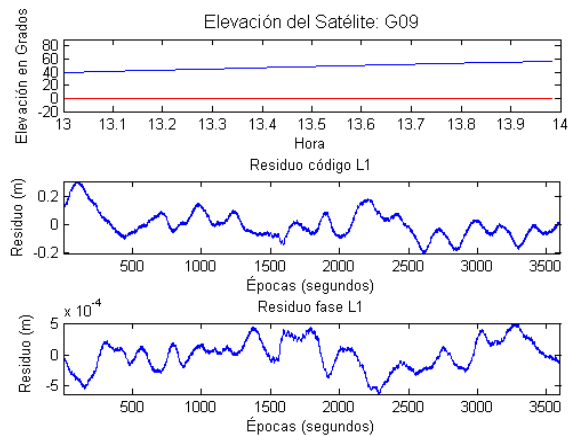

c)
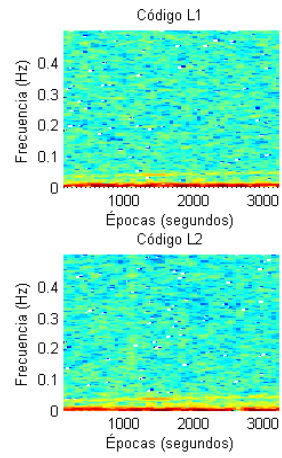

b)
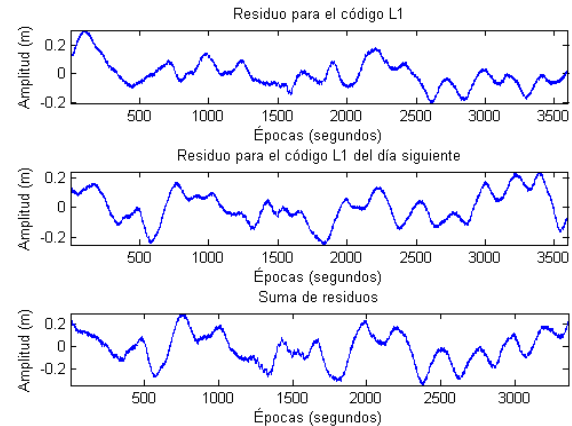

d)

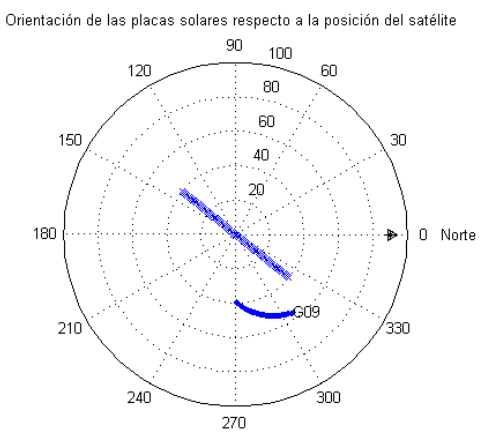

Fig. 8. a) Elevación del satélite G09 y series temporales de los residuos de código y fase para la frecuencia L1. b) Series temporales de los residuos de dos días consecutivos para el código L1 del satélite G09 y la suma de estos residuos. c) Espectrograma de las series temporales obtenidas para el satélite G09. d) Posición del satélite G09 respecto a las placas solares.

Posteriormente se aplica la función del espectrograma de MATLAB a esta serie temporal para encontrar señales con características similares al multipath. Una de las características del multipath es el comportamiento senoidal en torno $0.05 \mathrm{~Hz}$. En la figura 8c) se observa la presencia de frecuencias cercanas a $0.05 \mathrm{~Hz}$, se aprecia prácticamente durante toda la ventana de observación, pero con más potencia en la parte central de la misma. El multipath fue detectado durante el fin de semana de 11, 12 y 13 de junio de 2010 entre las horas 13-14 en el receptor G1. 
Como ya se dijo en la sección 4 el multipath es un efecto que depende en gran medida de la situación geométrica de cada caso particular. En la figura 8d) se muestra la posición del satélite respecto a las placas solares que hay instaladas en el edificio B-5 de la Universidad de Jaén. Se aprecia como el satélite G09 está situado enfrente de las placas, ésta es la razón por la cual se produce efecto multipath en las observaciones recibidas de este satélite. Se buscaron otros satélites donde apareciese el efecto multipath, pero no se encontró, ya que la situación geométrica no lo permitía. Además se estudiaron los datos procedentes de los receptores conectados a la antena choke ring LEIAT504, obteniéndose un efecto multipath más debilitado como era de esperar.

\subsubsection{Extracción de patrones}

La trasformada wavelet descrita en la sección 3.1.3 es una herramienta muy útil para extraer componentes de una señal. Sabiendo que el multipath tiene una frecuencia cercana a $0.05 \mathrm{~Hz}$, se utilizan hasta cuatro niveles de detalle como muestra la figura 9a).

En la simulación realizada en MATLAB, utilizando los datos obtenidos en el experimento para la extracción de patrones del efecto multipath, figuras 9b) y 9c), se aprecia como la señal de aproximación marca la tendencia y las señales D1, D2, D3 y D4 dan una información más detallada, es decir información relativa a frecuencias más altas.

En la figura 9c) se aprecia un aumento de la amplitud de la señal D4 entre las épocas 1200 y 1700 . La componente de detalle D4 contiene las frecuencias cercanas $0.05 \mathrm{~Hz}$. y de aquí se obtienen los patrones de multipath introducidos en el simulador.

Por último, se muestra una simulación del efecto multipath junto con los efectos troposférico e ionosférico para un satélite en el cénit, figura 9d).

Para terminar, comentar que el error de observación se ha modelado mediante una distribución aleatoria normal con media y desviación típica introducido por el usuario.

En las figuras 10a) y 10b) se muestra un ejemplo de una simulación de observación de código para un día de primavera considerando que tiene media nula y desviación típica $0.1 \mathrm{~m}$. 
a)

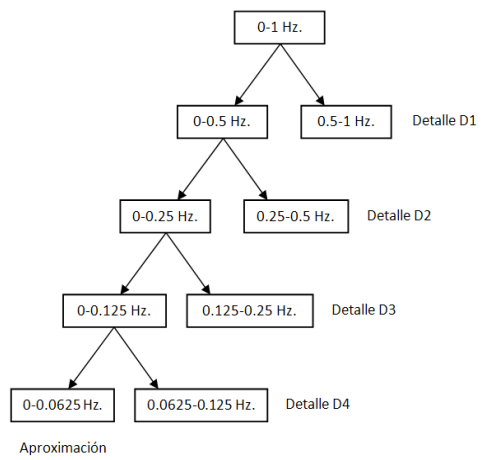

c)

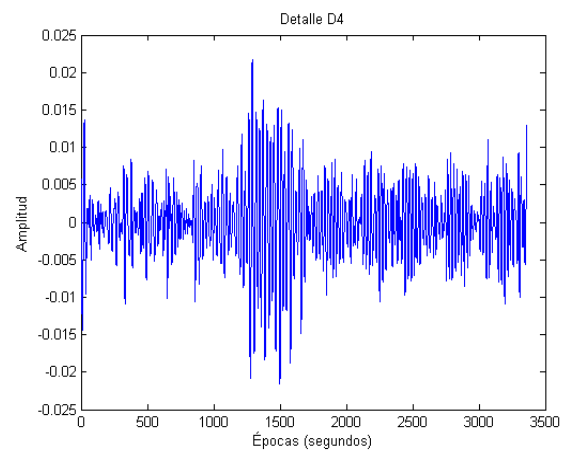

b)
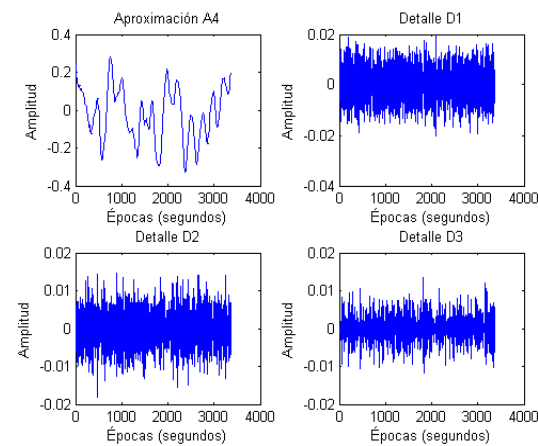

d)

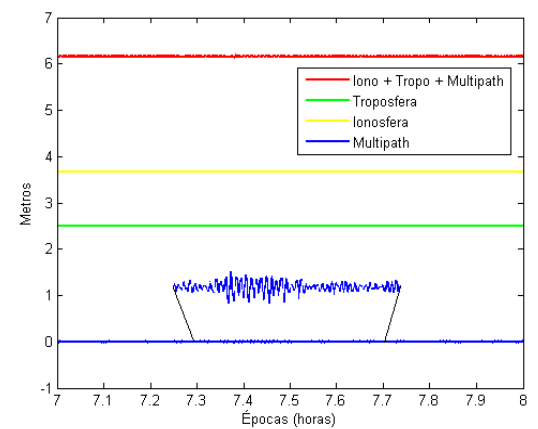

Fig. 9. a) Esquema jerárquico utilizado para extraer el multipath. b) Análisis wavelets. Señal de aproximación y señales de detalle $D 1, D 2$ y D3. c) Análisis wavelets. Señal de detalle $D 4$. d) Retardo ionosférico, troposférico y efecto multipath $(\mathrm{m})$ simulado a lo largo de una hora (7-8) para un satélite en el cenit.

a)

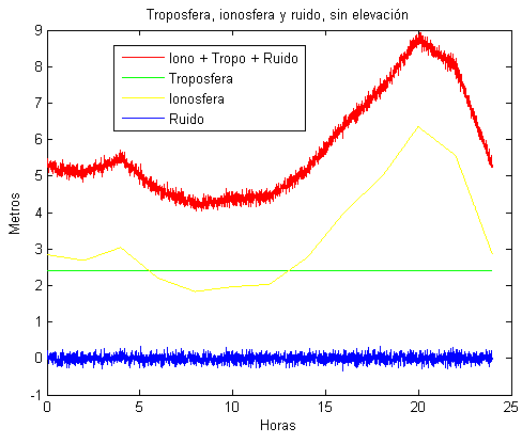

b)

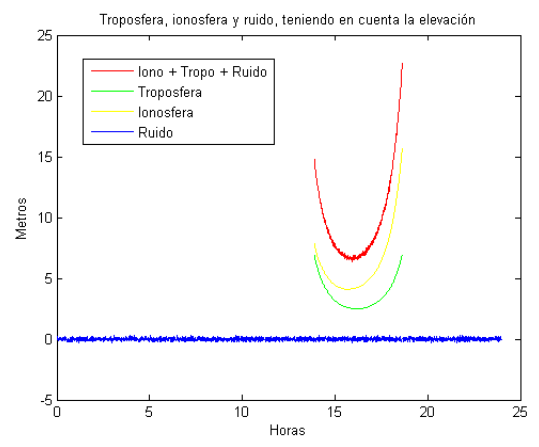

Fig. 10. a) Ejemplo de efecto ionosférico, troposférico y ruido para un satélite en el cenit. b) Ejemplo de efecto ionosférico, troposférico y ruido proyectados en la dirección satélitereceptor. 


\section{Conclusiones y trabajos futuros}

En este trabajo se han presentado los primeros pasos de un simulador de observaciones GNSS. Se han simulado e implementado, en lo que podríamos llamar un precursor del simulador, los efectos ionosféricos, troposféricos y de multipath. Los componentes atomosférico se han simulado a partir de modelos empíricos, como los mapas de TEC, los modelos globales de presión y temperatura y las funciones empíricas de proyección para la troposfera. Esto se ha hecho con la intención de conseguir unos datos simbólicos realistas que superan "el superoptimismo" de los simuladores existentes en el mercado. La parte innovadora del trabajo corresponde a la simulación del efecto de multipath que se ha realizado a partir de datos observados. Estos datos han sido procesados y se han analizado los residuos de días consecutivos. Se ha detectado el instante y duración del multipath y mediante el uso de wavelets se ha extraído un patrón de multipth que ha sido implementado en el simulador.

En los próximos meses este método será mejorado incluyendo en el análisis espectral la convolución de las series temporales de residuos de dos días consecutivos para optimizar el instante de repetición de las constelaciones. En este trabajo, el ruido de las observaciones ha sido simulado como una distribución normal de media cero y desviación típica $10 \mathrm{~cm}$ para la observación de código y de pocos $\mathrm{mm}$ para la de fase. El simulador final incluirá una parte en la que se emula el comportamiento de un oscilador atómico tanto del receptor como del satélite. Se pretende que al final todos los efectos presentes en la ecuación de observación (1.1) estén simulados de una forma fiable y realista en el simulador.

\section{Agradecimientos}

Este trabajo ha sido realizado dentro del proyecto "Nuevos algoritmos para el futuro sistema GNSS multifrecuencia" (Ref. AYA2008-02948), financiado por el Ministerio de Ciencia e Innovación.

\section{Referencias Bibliográficas}

ARINC Engineering Services (2006). NAVSTAR GPS space segment/navigation user interfaces. Interface specification, IS-GPS-200, revision D, IRN-200D-001, www.arinc.com/gps.

AGNEW, D.C., LARSON, K.M. (2006). Finding the repeat times of the GPS constellation. GPS Solutions, 11:71-76.

BAIOCCHI, V., CRESPI, M., PIETRANTONIO, G. (2007). A new software for the quality check of gps permanent stations data.

BANVILLE, S., LANGLEY, R.B. (2010). Instantaneous cycle slips correction for real time PPP applications. Navigation 57(4):325-334 
BERGEOT, N., BRUYNINX, C., DEFRAIGNE, P., PIREAUX, S., LEGRAND, J., POTTIAUX, E., BAIRE, Q. (2010). Impact of the halloween 2003 ionospheric storm on kinematic GPS positioning in europe. GPS Solutions.

BOEHM, J., HEINKELMANN, R., SCHUH, H. (2007). Short note: A global model of pressure and temperature for geodetic applications. Journal of Geodesy.

BOEHM, J., NIELL, A., TREGONING, P., SCHUH, H. (2006). Global mapping function (gmf): A new empirical mapping function based on numerical weather model data. Journal of Geophysical Research, 33.

COCARD, M., BOURGON, S., KAMALI, O., COLLINS, P. (2008). A systematic investigation of optimal carrier-phase combinations for modernized triplefrequency GPS. J Geod, 82:55-564.

DAI. Z., KNEDLIK, S., LOFFELD, O. (2009). Instantaneous triple-frequency GPS cycle-slip detection and repair. International Journal of Navigation and Observation.

DAUBECHIES, I. (1988). Orthonormal bases of compactly supported wavelets. Communications on Pure and Applied Mathematics, 41:906-966.

GRAPS, A. (1995). An introduction to wavelets. Technical report, Institute of Electrical and Electronics Engineers.

FENG, Y. (2008). GNSS three carrier ambiguity resolution using ionospherereduced virtual signal. J Geod, 82(12):847-862.

FENG, Y., RIZOS, C. (2009). Network-based geometry-free three carrier ambiguity resolution and phase bias calibration. GPS Solutions, 13(1):43-56.

HEISKANEN, W.A., MORITZ, H. (1967). Physical geodesy. Freeman, San Francisco.

HOFMANN-WELLENHOF, B., LICHTENEGGER, H., COLLINS, J. (1993). GPS Theory and Practice. Springer-Verlag New York Wien, 1993.

HOFMANN-WELLENHOF, B., LICHTENEGGER, H., WASLE, J. (2008). GNSS Global Navigation Satellite Systems. Springer Wien New York.

HOPFIELD, H.S. (1969). Two-quartic tropospheric refractivity profile for correcting satellite data. Journal of Geophysical Research, 74(18):4487-4499.

JI, S., CHEN, W., ZHAO, C., DING, X., CHEN, Y. (2007). Single epoch ambiguity resolution for Galileo with the CAR and LAMBDA methods. GPS Solutions, 11(4):259-268.

LACY, M.C. de, GIL, A.J., RODRÍGEZ-CADEROT, G., MORENO, B. (2008). A method to estimate the ionospheric bias by using the new gnss frequencies: an analysis of its theoretical accuracy in a ppp context. Física de la Tierra, 20:133150.

LACY, M.C. de, REGUZZONI, M., SANSÒ, F. (2012). A real time method for cycle-slip detection and correction in triple frequency GNSS observations. GPS Solutions, 16:353-362.

LARSON, K.M., BILICH, A., AXELRAD, P. (2007). Improving the precision of high-rate gps. Journal of Geophysical Research, 112. B05422. 
LI, B., FENG, Y., SHEN, Y. (2010). Three carrier ambiguity resolution: distanceindependent performance demonstrated using semigenerated triple frequency GPS signals. GPS Solutions, 14(2):177-184.

LIU, Z. (2011). A new automated cycle slip detection and repair method for a single dual-frequency GPS receiver. J Geod, 85:171-183.

MORENO, B., RADICELlA, S., DE LACY, M.C., HERRAIZ, M., RODRÍGUEZ-CADEROT, G. (2011). On the effects of the ionospheric disturbances on precise point positioning at equatorial latitudes. GPS Solutions, $15: 381-390$.

MORENO, B., RODRÍGUEZ-CADEROT, G., DE LACY, M.C. (2013). Multifrequency algorithms for precise point positioning: MAP3. GPS Solutions.

NEE, R.D.J. VAN. (1992). Multipath effects on gps code phase measurements. Navigation, 39(2):177-190.

NIELL A.E. (1996). Global mapping functions for the atmosphere delay at radio wavelengths. Journal of Geophysical Research, 101(B2):3227-3246.

ODIJK, D. (2003). Ionosphere-free phase combinations for modernized GPS. $J$ Survey Eng, 129(4):165-173.

OGAJA, C., SATIRAPOD, C. (2007). Analysis of high-frequency multipath in 1-hz gps kinematic solutions. GPS Solutions, 11:269-280.

OPPENHEIM, A.V., SCHAFER, R.W., BUCK, J.R. (1999). Discrete-Time Signal Processing. Prentice Hall.

PROAKIS, J.G., MANOLAKIS, D.K. (2007). Digital Signal Processing. Principles, Algorithms and Applications. Prentice Hall, 4th. Edition.

SAASTAMOINEN, J. (1973). Contribution to the theory of atmospheric refraction. Bulletin Géodésique, 107: 13-34.

SANSÒ, F. (2010). Il posizionamento da satellite (gnss). In Personal communication.

SCHAER, S., GURTNER, W., FELTENS, J. (1998). The ionosphere map exchange format version 1. In Proceedings of the IGS AC Workshop, Darmstadt, Alemania. SCHAER, S., STEIGENBERGER, P. (2006). Determination and use of gps differential code bias values. In Proceedings IGS workshop 2006, pages 8-11, Darmstadt, Germany.

TEUNISSEN, P.J.G., ODIJK, D. (2003). Rank defect integer estimation and phaseonly modernized GPS ambiguity resolution. J Geod, 76(9-10):259-268

WELLS, D.E., BECK, N., DELIKARAOGLOU, D., KLEUSBERG, A., KRAKIWSKY, E.J., LACHAPELLE, G., LANGLEY, R.B., NAKIBOGLU, M., SCHWARZ, K.P., TRANQUILLA, J.M., VANICEK, P. (1987). Guide to GPS positioning. Canadian GPS Associates, Fredericton.

ZHEN, D., STEFAN, K., OTMAR, L. (2008). Realtime cycle slip detection and determination for multiple frequency GNSS. In: Proceedings of the 5th workshop on positioning, navigation and communication 2008 (WPNC'08). 